\title{
The co-treatment of metformin with flavone synergistically induces apoptosis through inhibition of PI3K/AKT pathway in breast cancer cells
}

\author{
ZHAODI ZHENG, WENZHEN ZHU, BINGWU YANG, RONGFEI CHAI, TINGTING LIU, \\ FENGLIN LI, GUANGHUI REN, SHUHUA JI, SHAN LIU and GUORONG LI
}

Shandong Provincial Key Laboratory of Animal Resistant Biology, School of Life Sciences, Shandong Normal University, Jinan, Shandong 250014, P.R. China

Received February 8, 2017; Accepted January 24, 2018

DOI: $10.3892 / \mathrm{ol} .2018 .7999$

\begin{abstract}
Metformin, a widely used antidiabetic drug, exhibits anticancer effects which are mediated by the phosphatidylinositol 3-kinase (PI3K)/serine/threonine kinase (AKT) signaling pathway. However, its use in anticancer therapy combined with other natural products remains unclear. Flavone as the core structure of flavonoids has been demonstrated to induce cell apoptosis without causing serious side effect. Murine double minute $\mathrm{X}$ (MDMX) inhibits tumor suppressor gene p53 whose function is associated with the PI3K/AKT pathway. The results presented herein revealed that the combination of metformin and flavone significantly inhibited cell viability, and increased apoptosis of human breast cancer cells compared with metformin or flavone alone. The combination decreased the protein expression of MDMX, activated p53 through the $\mathrm{PI} 3 \mathrm{~K} / \mathrm{AKT}$ signaling pathway, regulated $\mathrm{p} 53$ downstream target genes Bcl-2 apoptosis regulator, BCL2 associated X apoptosis regulator and cleaved caspase3, subsequently inducing apoptosis in MDA-MB-231 and MCF-7 breast cancer cells. These results indicated that dietary flavone may potentiate breast cancer cell apoptosis induced by metformin, and PI3K/AKT is involved in regulating MDMX/p53 signaling. This data suggests that dietary supplementary of flavone is a promising strategy for metformin mediated anticancer effects.
\end{abstract}

\section{Introduction}

PI3K/AKT signaling pathway plays an important role in the development of numerous types of tumors as it is involved in cell growth, proliferation and apoptosis (1-3). There are several

Correspondence to: Professor Guorong Li, Shandong Provincial Key Laboratory of Animal Resistant Biology, School of Life Sciences, Shandong Normal University, 88 East Wenhua Road, Jinan, Shandong 250014, P.R. China

E-mail: grli@sdnu.edu.cn

Key words: metformin, flavone, PI3K, MDMX/p53, apoptosis pathways that PI3K/AKT regulates its downstream targets. PI3K/AKT indirectly inhibits mTOR to cause cell cycle arrest and cell apoptosis (4). AKT activates MDM2 indirectly to decrease p53 level and activity, and promote p53 translation and protein stability (5-7).

Metformin is a biguanide used as an oral anti-diabetic drug, and the Food and Drug Administration (FDA) recently has approved the first clinical study to investigate its protective effects against numerous comorbidities. It has received attention as a potential therapeutic agent for cancer treatment $(8,9)$. Trametinib and paclitaxel are well-known chemotherapeutic drugs, which are frequently used to treat breast and lung cancers, and both have synergistic effects when used in combination with metformin $(4,10)$. Metformin exerts anti-proliferative activity on glioblastoma cells by inhibiting AKT signaling (11). Metformin induces p53 activity by regulating AMPK/mTOR signaling pathway $(10,12)$ and activates AMPK to phosphorylate and inactivate MDMX, finally results in stabilization and activation of p53 in cancer cells (13). As a major p53 repressor, MDMX overexpresses in many human cancers, which inhibits DNA repair signals and promotes transformation to contribute to tumorigenesis. When MDMX is inhibited, the activity of p53 is enhanced and p53 degradation is blocked (14).

Flavonoids are safe and easily obtainable by extraction from natural plants. Many of them are part of human daily diet $(15,16)$. Flavonoids inhibit PI3K/AKT pathway to induce apoptosis $(17,18)$. Tangeretin inhibits growth of HL-60 cells and induces apoptosis without causing serious side-effect on immune cells (19). Luteolin has low incidence of side effects in therapeutic potential (20). Pre-treatment with cardamonin significantly attenuates nephrotoxic effects, oxidative stress, inflammation and decreases caspase 3 expression and $\mathrm{Bax} / \mathrm{Bcl}-2$ ratio induced by cisplatin (21). Flavone (2-phenyl-4H-1-benzopyran-4-one) is the core structure of flavonoids, which induces apoptosis potent in human colon carcinoma cells $(22,23)$. Flavone inhibits PI3K/AKT and increases FoxO3a activation to induce apoptosis in breast cancer cells (24).

The PI3K/AKT pathway that metformin mediated with or without flavonoids remains to be fully determined in breast cancer cells. Inhibition of PI3K/AKT pathway may gain importance as potential mono- and combination therapies 
in the clinical trials. Therefore, our study was designed to investigate whether flavone enhances cell apoptosis induced by metformin and whether the combination shares a common intracellular signal pathway that regulates MDMX/p53 via PI3K/AKT in breast cancer cells.

\section{Materials and methods}

Reagents and antibodies. Metformin (MET) and flavone (FLA) were purchased from Sigma-Aldrich (St. Louis, MO, USA). Antibodies against PI3K (cat. no. 4249S), p-AKT(ser-473) (cat. no. 4060S) and caspase3 (cat. no. 8665P) were from Cell Signaling Technology (Danvers, MA, USA); MDMX (cat. no. sc-14738) from Santa Cruz Biotechnology (Dallas, TX, USA); p53 (cat. no. BS1272) and Bax (cat. no. BS1030) from Bioworld Technology, Inc. (St. Louis Park, MN, USA). AKT1 (cat. no. BF0570), Bcl-2 (cat. no. AF0769) and cleaved caspase3 (cat. no. AF7022) were from Affinity Biosciences (Cincinnati, OH, USA); $\beta$-actin (cat. no. 60008-1-lg) was from ProteinTech Group, Inc. (Chicago, IL, USA). PI3K inhibitor (LY294002) was obtained from Beyotime Institute of Biotechnology (Haimen, China).

Cell culture. MCF-10A human breast epithelial cells, MDA-MB-231 and MCF-7 human breast cancer cells were from American Type Culture Collection (Manassas, VA, USA). Cells were cultured in Dulbecco's modified Eagle's medium supplemented with $10 \%$ fetal calf serum, and maintained at $37^{\circ} \mathrm{C}$ in humidified atmosphere with $5 \% \mathrm{CO}_{2}$.

MTT assay. MTT assay is based on the conversion of MTT (Amresco, LLC, Solon, OH, USA) to formazan crystals by mitochondrial dehydrogenases. Briefly, MDA-MB-231 cells were plated in 96-well plates at a density of $1 \times 10^{4}$ cells per well for $16 \mathrm{~h}$. The cells were respectively treated with flavone and metformin under various concentrations $(100,150,200$, $250 \mu \mathrm{M})$ and $(5,10,15,20,25 \mathrm{mM})$ for $24 \mathrm{~h}$ to select a suitable inhibitory concentration. Similarly, the cells were treated with $10 \mathrm{mM}$ metformin, $10 \mathrm{mM}$ metformin: $100 \mu \mathrm{M}$ flavone, $10 \mathrm{mM}$ metformin:200 $\mu \mathrm{M}$ flavone; and $20 \mathrm{mM}$ metformin, $20 \mathrm{mM}$ metformin: $100 \mu \mathrm{M}$ flavone, $20 \mathrm{mM}$ metformin: $200 \mu \mathrm{M}$ flavone for $24 \mathrm{~h}$. Then MTT solution $(5 \mathrm{mg} / \mathrm{ml})$ was added $(20 \mu \mathrm{l} /$ well $)$ to the precipitate and incubated at $37^{\circ} \mathrm{C}$ for $4 \mathrm{~h}$. The solution was aspirated, and the formazan crystals were dissolved with $150 \mu \mathrm{l}$ DMSO (Amresco, LLC). The absorbance was measured at $492 \mathrm{~nm}$ by an enzyme-linked immunosorbent assay reader (Awareness Technology, Inc., Palm City, FL, USA).

Hoechst/propidium iodide (PI) staining. MCF-10A, MDA-MB-231 and MCF-7 cells were exposed to $20 \mathrm{mM}$ metformin, $20 \mathrm{mM}$ metformin:100 $\mu \mathrm{M}$ flavone for $24 \mathrm{~h}$ and stained with Hoechst 33342 and PI (Beyotime Institute of Biotechnology) for 20-30 min. The nuclei of apoptotic cells were observed visually by fluorescence microscope. The cells were differentiated with normal live cells (exhibited light blue), apoptotic cells (exhibited bright blue) and necrotics cells (exhibited red).

Western blot analysis. The cells were treated with $20 \mathrm{mM}$ metformin, $100 \mu \mathrm{m}$ flavone and $20 \mathrm{mM}$ metformin:100 $\mu \mathrm{M}$ flavone for $24 \mathrm{~h}$. Protein concentration was determined by the BCA Assay (Thermo Fisher Scientific, Inc., Waltham, MA, USA). An equal amount of protein from each sample was loaded per lane, separated by SDS-PAGE and transferred onto a polyvinylidene difluoride membrane. The membrane was blocked in 5\% milk for $90 \mathrm{~min}$ at room temperature, incubated with primary antibodies overnight at $4^{\circ} \mathrm{C}$, then washed 3 times and incubated with appropriate HRP-conjugated secondary antibodies. After washing, protein expression was detected with the ECL system (Beyotime Institute of Biotechnology).

Statistical analysis. Each experiment was analysed in three biological replicates. Data were expressed as mean \pm standard deviation. Multiple comparisons between the groups have been performed using $\mathrm{S}-\mathrm{N}-\mathrm{K}$ method after ANOVA. P-values of $<0.05$ were considered statistically significant.

\section{Results}

Combined metformin and flavone inhibits cell viability, and induces apoptosis. MDA-MB-231 cells were treated by 0, 5, $10,15,20$ and $25 \mathrm{mM}$ metformin for $24 \mathrm{~h}$, the inhibition rates on cell viability were $0,7.64 \pm 5.90,13.51 \pm 0.35,13.10 \pm 0.39$, $20.93 \pm 1.038$ and $24.20 \pm 0.012 \%$, the inhibitory effects on cell viability increased with the extension of treatment concentrations, and cells were sensitive to $10 / 20 \mathrm{mM}$ metformin treatment. The inhibition rates were $0,3.83 \pm 7.30,9.15 \pm 8.14$, $18.97 \pm 2.94$ and $19.67 \pm 3.78 \%$, respectively when treated by $0,100,150,200$, and $250 \mu \mathrm{M}$ flavone for same time. Cell viability was inhibited by 150,200 and $250 \mu \mathrm{M}$ flavone and was not significantly effected by $100 \mu \mathrm{M}$ flavone $(\mathrm{P}<0.05$ and $\mathrm{P}<0.01$; Fig. 1A). The concentrations of 10 and $20 \mathrm{mM}$ metformin were chosen for the combination treatment. When $100 / 200 \mu \mathrm{M}$ flavone was supplemented to the cells which were treated with $10 \mathrm{mM}$ metformin for $24 \mathrm{~h}$, the inhibition rates increased to $24.3 \pm 1.5$ and $24.9 \pm 1.5 \%$ respectively compared to an inhibition rate of $15.7 \pm 0.2 \%$ with $10 \mathrm{mM}$ metformin only. Similarly, when $100 / 200 \mu \mathrm{M}$ flavone was added to the cells treated with $20 \mathrm{mM}$ metformin, the inhibition rates became higher (34.0 \pm 1.9 and $36.8 \pm 1.4 \%$, respectively) than $20 \mathrm{mM}$ metformin only $(24.6 \pm 2.5 \%)$. The results demonstrated that combination treatment of metformin and flavone increased significantly inhibition rates to the breast cancer cells $(\mathrm{P}<0.05$ and $\mathrm{P}<0.01$; Fig. 1B). The inhibition rates were higher when the cells treated by $20 \mathrm{mM}$ metformin combined with $100 / 200 \mu \mathrm{M}$ flavone than that by $10 \mathrm{mM}$ metformin with same concentration flavone. Meanwhile, the inhibition rates had no change when the cells co-treated by $10 / 20 \mathrm{mM}$ metformin with $100 / 200 \mu \mathrm{M}$ flavone respectively. The combination of $20 \mathrm{mM}$ metformin:100 $\mu \mathrm{M}$ flavone was used for the following experiments.

To investigate effects of metformin and flavone on cell apoptosis, Hoechst and PI nuclear staining assay were performed. The apoptosis rates were $2.71 \pm 0.81$ and $2.86 \pm 0.79 \%$ in MCF-10A, $6.43 \pm 0.78$ and $9.96 \pm 0.94 \%$ in MDA-MB-231 and $5.89 \pm 1.02$ and $9.37 \pm 0.86 \%$ in MCF-7 after metformin or combination treatment compared to $3.16 \pm 0.95,4.23 \pm 0.90$ and $3.46 \pm 0.80 \%$ of control groups, respectively $(\mathrm{P}<0.05$ and $\mathrm{P}<0.01$; Fig. $1 \mathrm{C}$ and D). Our results revealed that $\mathrm{MCF}-10 \mathrm{~A}$ cells were less sensitive to metformin or combination-induced 

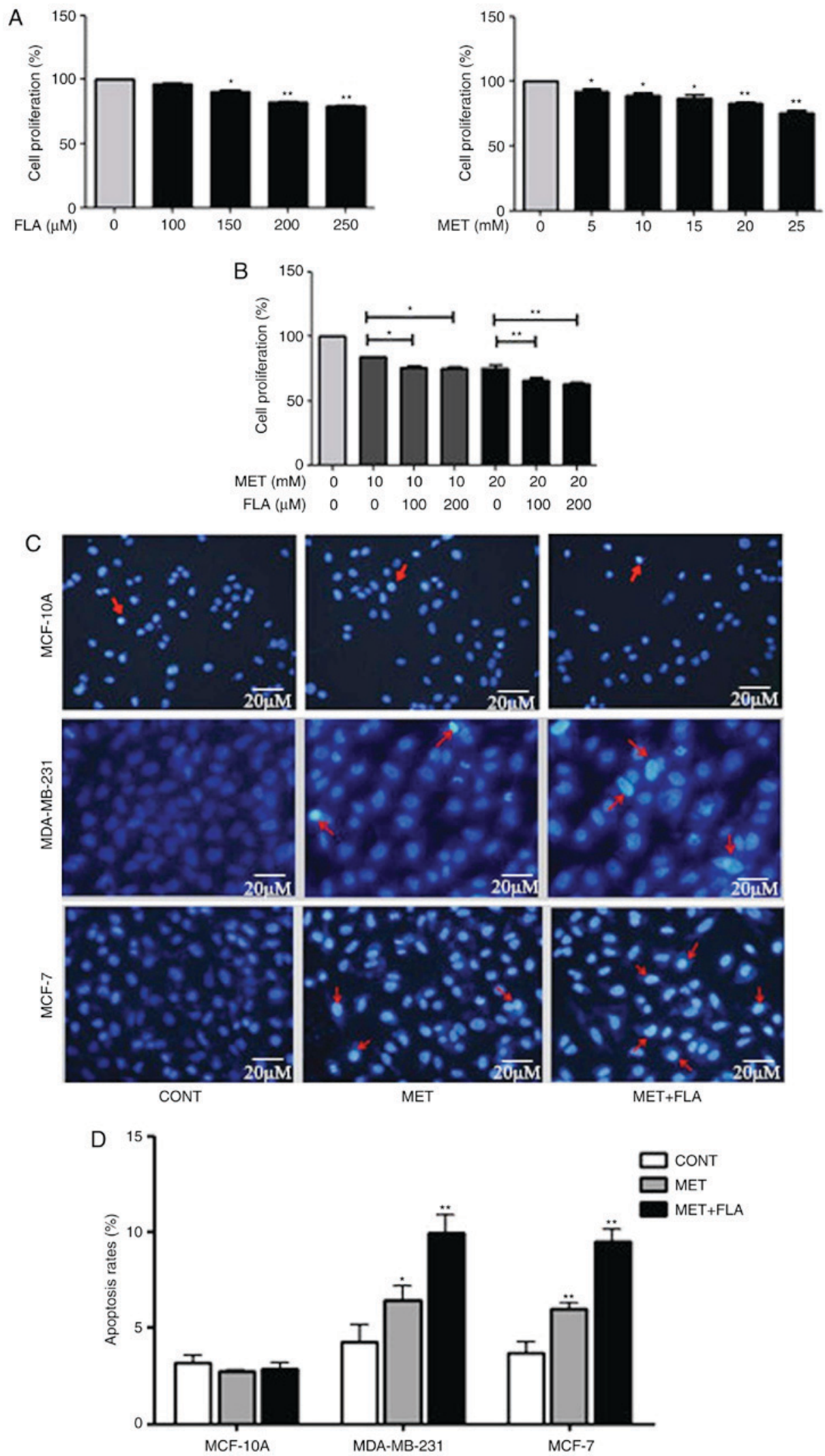

Figure 1. The combination of metformin and flavone inhibited cell viability and induced apoptosis in breast cancer cells with a concentration dependent manner (A) MDA-MB-231 cell viability was measured after treatment with FLA $(0,100,150,200,250 \mu \mathrm{M})\left({ }^{*} \mathrm{P}<0.05,150 \mu \mathrm{M}\right.$ FLA vs. control; ${ }^{* * *} \mathrm{P}<0.01,200 \mu \mathrm{M}$ FLA vs. control, $250 \mu \mathrm{M}$ FLA vs. control) and MET under various concentrations $(0,5,10,15,20,25 \mathrm{mM})$ ("P $<0.05,5 \mathrm{mM}$ MET vs. control, $10 \mathrm{mM}$ MET vs. control, $15 \mathrm{mM}$ MET vs. control; ${ }^{* *} \mathrm{P}<0.01,20 \mathrm{mM}$ MET vs. control, $25 \mathrm{mM}$ MET vs. control) for $24 \mathrm{~h}$. (B) MDA-MB-231 cells were treated by $10 \mathrm{mM}$ MET, $10 \mathrm{mM}$ MET:100 $\mu$ M FLA, $10 \mathrm{mM}$ MET:200 $\mu \mathrm{M}$ FLA and treated by $20 \mathrm{mM}$ MET, $20 \mathrm{mM}$ MET:100 $\mu \mathrm{M}$ FLA, $20 \mathrm{mM}$ MET:200 $\mu \mathrm{M}$ FLA for $24 \mathrm{~h}(" \mathrm{P}<0.05,10 \mathrm{mM}$ MET:100 $\mu$ M FLA vs. $10 \mathrm{mM}$ MET, $10 \mathrm{mM}$ MET:200 $\mu$ M FLA vs. $10 \mathrm{mM}$ MET; ${ }^{* *} \mathrm{P}<0.01,20 \mathrm{mM}$ MET:100 $\mu \mathrm{M}$ FLA vs. $20 \mathrm{mM}$ MET, $20 \mathrm{mM}$ MET:200 $\mu \mathrm{M}$ FLA vs. $20 \mathrm{mM}$ MET). (C) Representative photomicrographs of MCF-10A, MDA-MB-231 cells stained with Hoechst 33342 and propidium iodide fluorescent dye after incubated in the treatment with $20 \mathrm{mM}$ MET, $20 \mathrm{mM}$ MET:100 $\mu \mathrm{M}$ FLA for $24 \mathrm{~h}$. The arrows show the apoptotic cells distinguished by condensed or fragmented nuclei. (D) The quantitative results of apoptosis rates with different treatment ("P $<0.05,20 \mathrm{mM}$ MET vs. control; ${ }^{* * *} \mathrm{P}<0.01,20 \mathrm{mM}$ MET:100 $\mu \mathrm{M}$ FLA vs. control) and MCF-7 ("P<0.01, 20 mM MET vs. control, 20 mM MET:100 $\mu$ M FLA vs. control). FLA, flavone; MET, metformin. 

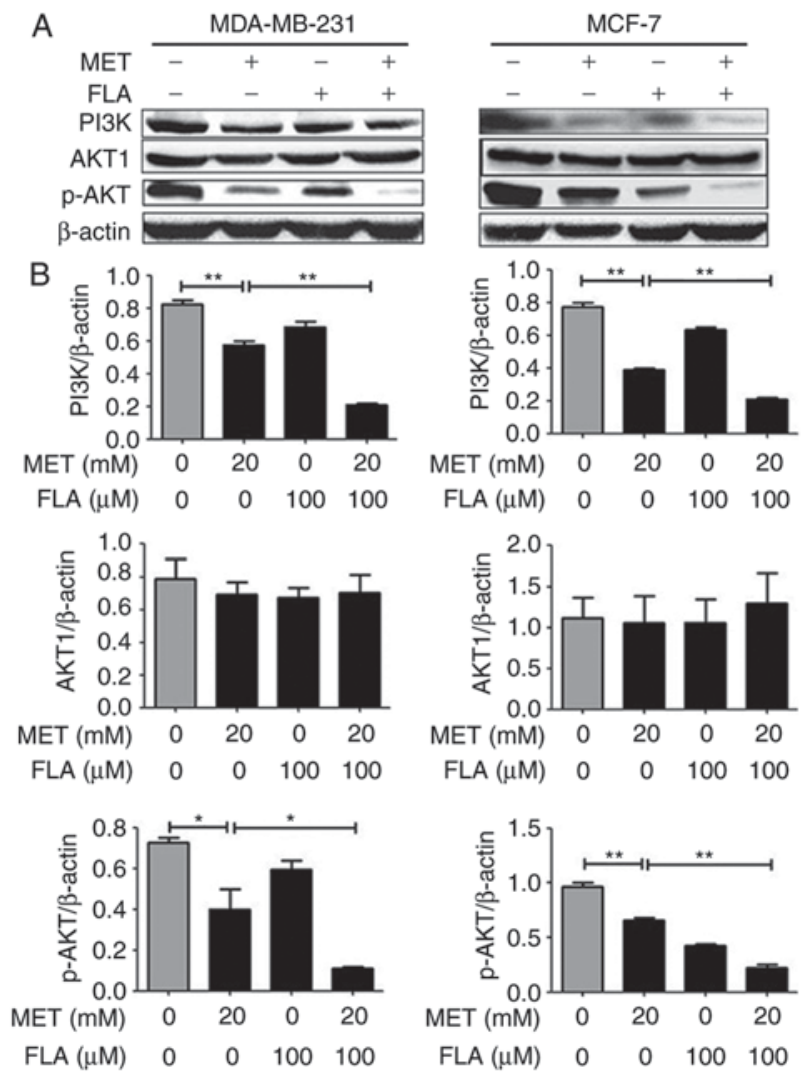

Figure 2. The combination of metformin and flavone synergistically inhibited the PI3K/AKT pathway in breast cancer cells. (A) Protein levels for PI3K , AKT and p-AKT(ser-473) were detected with western blotting when MDA-MB-231 cells (left column) were treated with $0,20 \mathrm{mM}$ MET, $100 \mu \mathrm{M}$ FLA and the combination of $20 \mathrm{mM}$ MET:100 $\mu \mathrm{M}$ FLA for $24 \mathrm{~h}$, and MCF-7 cells (right column) were the same treatment to test PI3K, AKT and p-AKT(ser-473) expressions, (B) and their densitometry results over $\beta$-actin at least three separate experiments. ${ }^{* *} \mathrm{P}<0.01,20 \mathrm{mM}$ MET vs. control, $20 \mathrm{mM}$ MET:100 $\mu \mathrm{M}$ FLA vs. $20 \mathrm{mM}$ MET; ${ }^{2} \mathrm{P}<0.05,20 \mathrm{mM}$ MET vs. control, $20 \mathrm{mM}$ MET:100 $\mu \mathrm{M}$ FLA vs. 20 mM MET. PI3K, phosphatidylinositol 3-kinase; AKT, serine/ threonine kinase; FLA, flavone; MET, metformin.

apoptosis than MDA-MB-231 or MCF-7 cells respectively. Metformin and co-treatment increased breast cancer cell apoptosis but barely affected on MCF-10A cells, and the higher apoptosis rate appeared by co-treatment than metformin treatment in MDA-MB-231 and MCF-7 cells.

Combined metformin and flavone synergistically inhibits the PI3K/AKT pathway. In MDA-MB-231 and MCF-7 cells, the results of western blotting showed that metformin, flavone and co-treatment had no effect on AKT1 expression, but metformin decreased PI3K and p-AKT(ser-473) protein levels compared with control group. The combination of metformin and flavone significantly decreased expressions of PI3K and p-AKT compared to metformin or flavone single-treatment $(\mathrm{P}<0.05$ and $\mathrm{P}<0.01$; Fig. 2). These results showed that induction of cell apoptosis may involve modulation of the PI3K/AKT signaling via the combination treatment.

PI3K/AKT pathway is associated with $M D M X / p 53$ regulation for treatment with the combination of metformin and flavone. When two cell lines were treated with metformin or flavone alone, MDMX expression decreased and p53 increased. When
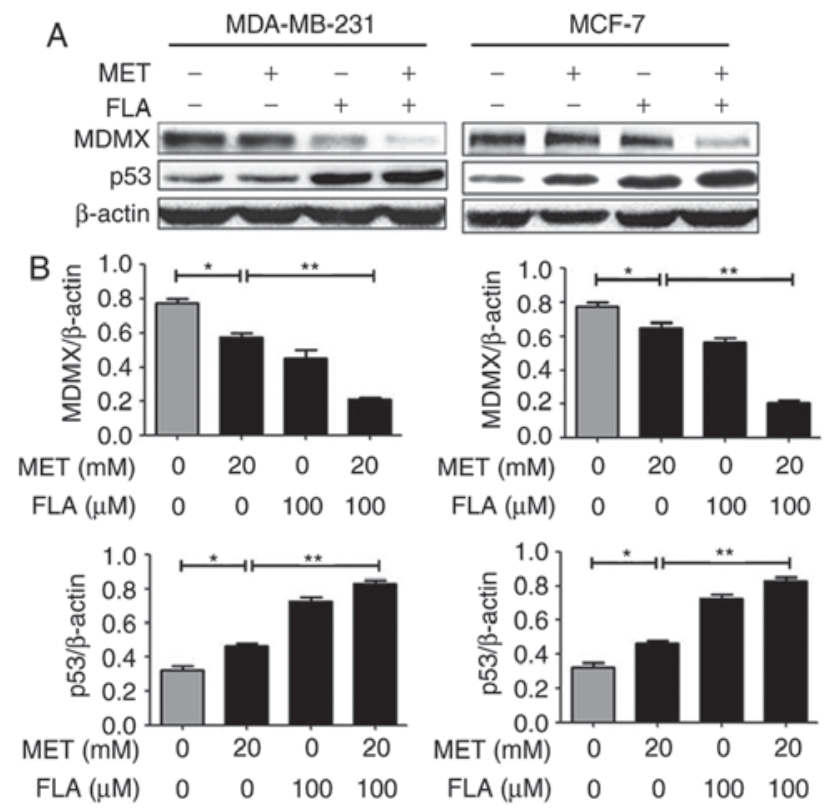

Figure 3. The combination of metformin and flavone regulated MDMX and p53 expressions. (A) Western blotting revealed the expression levels of MDMX and p53 when MDA-MB-231 and MCF-7 cells treated with 0, $20 \mathrm{mM}$ MET, $100 \mu \mathrm{M}$ FLA and the combination of $20 \mathrm{mM}$ MET:100 $\mu \mathrm{M}$ FLA for 24 h. (B) Bar graphs showed their relative levels to $\beta$-actin. ${ }^{*} \mathrm{P}<0.05$, $20 \mathrm{mM}$ MET vs. control; ${ }^{* *} \mathrm{P}<0.01,20 \mathrm{mM}$ MET:100 $\mu \mathrm{M}$ FLA vs. $20 \mathrm{mM}$ MET. MDMX, murine double minute X; FLA, flavone; MET, metformin.

flavone was supplemented together into the cells, the effects of metformin were potentiated $(\mathrm{P}<0.05$ and $\mathrm{P}<0.01$; Fig. 3 ). These results suggested that the combination induced apoptosis by reducing MDMX and up-regulating p53 level.

To further examine the relationship of p53 with PI3K/AKT pathway after the combination treatment, PI3K inhibitor LY294002 was used to examine p53 expression. An increase in p53 protein level appeared when the cells were treated with combination or LY294002 compared to control group. p53 levels increased significantly when LY294002 was added to co-treatment compared to combination group or LY294002 in MDA-MB-231 and MCF-7 cells ( $\mathrm{P}<0.05$ and $\mathrm{P}<0.01$; Fig. 4).

Combined metformin and flavone regulates the expression of apoptosis-associated proteins. Bcl-2 and Bax are p53-dependent target genes. Our results showed that metformin, flavone and co-treatment decreased Bcl-2, and increased Bax as well as cleaved caspase 3 expressions, but it had no effect on caspase 3 level. Combination group showed higher expression of cleaved caspase 3 than metformin or flavone group. These results showed that metformin, flavone and co-treatment induced apoptosis via apoptotic protein $\mathrm{Bcl}-2$, Bax and caspase pathway in breast cancer cells $(\mathrm{P}<0.05$ and $\mathrm{P}<0.01$; Fig. 5).

\section{Discussion}

Metformin is an oral anti-diabetic drug and has a well-known safety profile. It interferes with PI3K/AKT pathway to induce apoptosis in many cancer cells $(11,25,26)$. AKT can activate eIF4E by inhibiting mTOR to enhance cyclin D1, resulting in cell cycle arrest in G1 phase $(27,28)$. As a novel AMPK activator, metformin increases nuclear accumulation and protein 

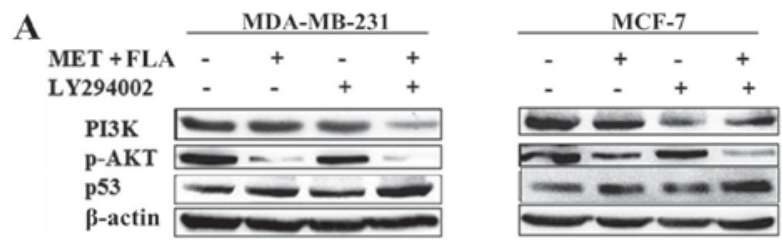

B
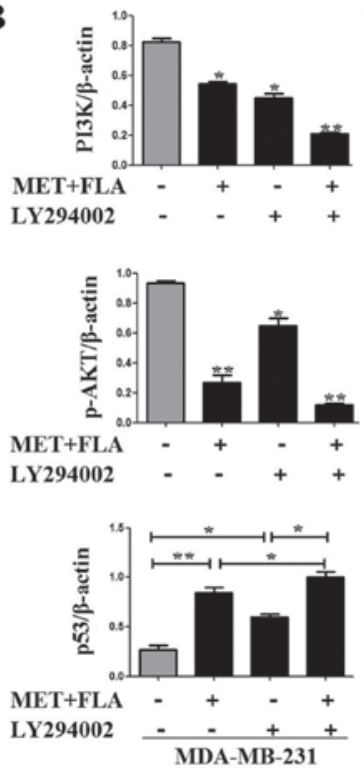
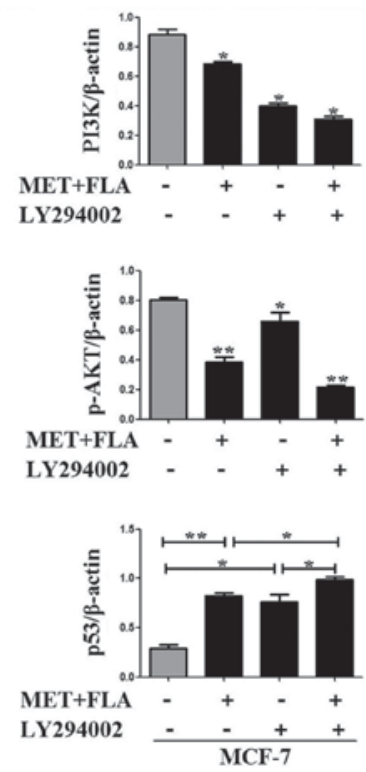

Figure 4. PI3K/AKT pathway was associated with MDMX/p53 regulation treated with the combination of metformin and flavone. (A) Expressions of PI3K ( $\mathrm{P}<0.05$, combination vs. control, LY294002 vs. control; ${ }^{* *} \mathrm{P}<0.01$, the combination and LY294002 vs. control), p-AKT(ser-473) ("P<0.05, LY294002 vs. control; ${ }^{* *} \mathrm{P}<0.01$ combination vs. control, the combination and LY294002 vs. control) and p53 ("P<0.05, LY294002 vs. control, the combination and LY294002 vs. combination, the combination and LY294002 vs. LY294002; * $\mathrm{P}<0.01$, combination vs. control) with 0 , the combination, LY294002, the combination and LY294002 treatment in MDA-MB-231 cells. MCF-7 cells were the same treatment to detect PI3K ( ${ }^{*} \mathrm{P}<0.05$, combination vs. control, Ly294002 vs. control, the combination and LY294002 vs. control), p-AKT(ser-473) ("P<0.05, LY294002 vs. control; ${ }^{* *} \mathrm{P}<0.01$, combination vs. control, the combination and LY294002 vs. control) and p53 ("P<0.05, LY294002 vs. control, the combination and LY294002 vs. combination, the combination and LY294002 vs. LY294002; ${ }^{* *} \mathrm{P}<0.01$, combination vs. control) expression. (B) Bar graphs showed their relative levels to $\beta$-actin. PI3K, phosphatidylinositol 3-kinase; AKT, serine/threonine kinase; MDMX, murine double minute X; FLA, flavone; MET, metformin.

stability of FoxO3a by inhibiting AKT-MDM2 signaling pathway to reduce invasive and metastatic capacity of aggressive cancer cells (29). Therefore, PI3K/AKT pathway plays a significant role in anticancer effects.

Flavone inhibits PI3K/AKT pathway to involve in the progression and apoptosis of cancer cells $(18,30,31)$. Our previous results have presented that $100 \mu \mathrm{M}$ flavone reduced viability slightly in breast cancer cells (32). We herein showed that metformin monotherapy had low inhibition rates on cell viability and apoptosis (Fig. 1A and C). The addition of flavone to metformin led to enhance anti-cancer effects of metformin (Fig. 1B and C). Apoptosis rates are 27 and $37 \%$ for the cells treated with flavone compared to 13 and $25 \%$ for control group respectively in MDA-MB-231 and MCF-7 cells (24). Apoptosis is increased about 2.4- to 3.1 -fold induced by flavonoid for $36 \mathrm{~h}$ in LNCaP cells (33). Our previous study showed that apoptotic rate was $15.15 \pm 0.20 \%$ when treated by $200 \mu \mathrm{M}$ flavone compared to $4.90 \pm 1.23 \%$ of control group in breast cancer cells (32).

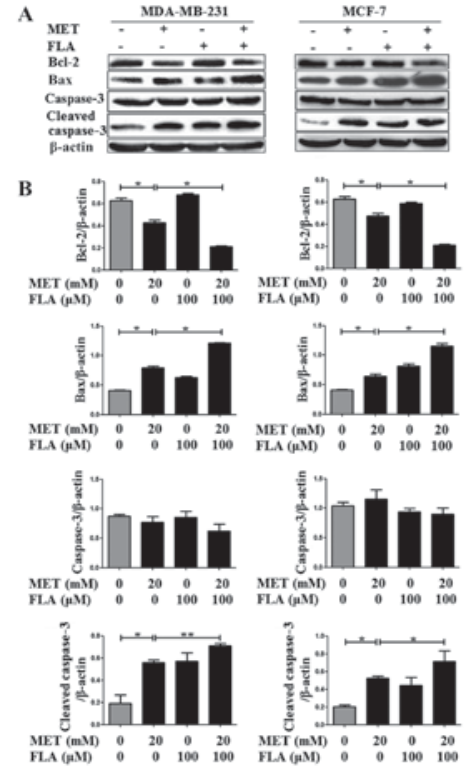

Figure 5. The combination of metformin and flavone regulated downstream targets of p53. (A) Protein levels of Bcl-2, Bax were detected with western blotting when MDA-MB-231 and MCF-7 cells were treated with $0,20 \mathrm{mM}$ MET, $100 \mu \mathrm{M}$ FLA and the combination of $20 \mathrm{mM}$ MET:100 $\mu \mathrm{M}$ FLA for $24 \mathrm{~h}($ ("P $<0.05,20 \mathrm{mM}$ MET vs. control, $20 \mathrm{mM}$ MET:100 $\mu$ M FLA vs. $20 \mathrm{mM}$ MET), caspase 3 were detected no significance and cleaved caspase 3 were detected when MDA-MB-231 ("P $<0.05,20 \mathrm{mM}$ MET vs. control; * ${ }^{* *}<<0.01$, $20 \mathrm{mM}$ MET:100 $\mu \mathrm{M}$ FLA vs. $20 \mathrm{mM}$ MET) and MCF-7 cells ("P $<0.05$, $20 \mathrm{mM}$ MET vs. control, $20 \mathrm{mM}$ MET:100 $\mu$ M FLA vs. $20 \mathrm{mM}$ MET) were the same treatment, (B) and their densitometry results over $\beta$-actin in at least three separate experiments. FLA, flavone; MET, metformin.

Apoptosis rates in our results increased 1.5- to 3 -fold. It is consistent with others' results. Similarly, metformin decreased PI3K and p-AKT(ser-473) protein expressions compared with control group. When the cancer cells were treated with the combination, PI3K and p-AKT(ser-473) protein levels became lower than those in metformin treatment (Fig. 2). Therefore, the combination treatment significantly decreased expressions of PI3K and p-AKT(ser-473). MCF-7 cells represent an ERa positive model and MDA-MB-231 ERa negative. Both cells are PTEN inactive mutation (34). In addition, mTORC2 can regulate AKT phosphorylation at S473 and induce cellular signal pathway in human wild-type PTEN or PTEN-null cancer cell lines (35). Therefore, the constitutive AKT activation after PI3K inhibitor treatment might due to deregulated p-AKT level by mTORC2 inhibition with co-treatment other than dependence on PI3K only.

MDMX binds to p53 and is involved in inhibiting p53 transactivation activity, which represses function of p53 and destabilizes the protein in breast cancer cells $(14,36)$. Our data indicated that metformin reduced MDMX level and activated p53 to regulate apoptosis-related proteins. It is in accordance with a previous result that metformin phosphorylates and inactivates MDMX to activate p53 in HCT116 colon cancer cells (13). The combination of metformin and flavone markedly inhibited MDMX and activated p53 compared to metformin treatment only. Flavone supplement enhanced the regulation of metformin on MDMX and p53 (Fig. 3). When MDMX was inhibited, p53 expression was enhanced, which showed that the combination increased p53 level through inhibiting MDMX. Some reports suggest that PI3K/AKT/p53 was activated by 
mammalian reovirus to inhibit virus replication/infection (37). A p53 target gene, Sesn2, is independent of p53 but requires the PI3K/AKT pathway to protect cells against oxidative and genotoxic stresses (38). Pacilitaxel can promote apoptosis and growth inhibition of human nasopharyngeal cancer cell line CNE2 by suppressing PI3K, p-AKT and increasing p53 level (39). However, the molecular mechanism of PI3K/AKT pathway regulates MDMX/p53 is presently unclear when the cancer cells were treated with combination of metformin and flavone. In our study, p53 expression significantly increased after co-treatment and LY294002 treatment (Fig. 4), indicating that p53 was the downstream of PI3K and the combination increased expression of $\mathrm{p} 53$ by inhibiting PI3K/AKT pathway. Although the mechanism was not fully understood, it brings unexpected insight into PI3K/AKT-mediated regulation of $\mathrm{MDMX} / \mathrm{p} 53$ on apoptosis by co-treatment in breast cancer cells.

p53 directly activates apoptosis-related Bax to induce release of cytochrome $\mathrm{c}$ from mitochondria, and then activates caspase (40). In addition, p53 reduces Bcl-2 transcription (41). Flavones induce caspase-dependent apoptosis in A549 cells (42) and primary human neutrophils (43). Our present study showed that metformin, flavone and combination induced apoptosis by decreasing Bcl-2, increasing Bax and cleaved caspase 3 protein level.

Taken together, it is the first time for the combination of metformin and flavone to inhibit cell viability and to induce apoptosis more effectively than metformin and flavone alone in breast cancer cells. The combination potentiated apoptosis by decreasing MDMX and increasing p53 expression via PI3K/AKT signaling pathway. Further studies should be performed to fully define the action of the combination and underlying mechanism in vivo, and this combination will be a promising approach for clinical cancer therapy.

\section{Acknowledgements}

The present study was supported by the National Natural Science Foundation of China (grant no. 31672377), Major Key Technology of Science and Technology in Shandong Province (2015ZDJS04003), the Key Program of Shandong Provincial Natural Science Foundation of China (ZR2013CZ002), Science and Technology Program of Jinan (201202033).

\section{References}

1. Vivanco I and Sawyers CL: The phosphatidylinositol 3-kinaseAKT pathway in human cancer. Nat Rev Cancer 2: 489-501, 2002.

2. Liu Y, Zhang Y, Jia K, Dong Y and Ma W: Metformin inhibits the proliferation of A431 cells by modulating the PI3K/Akt signaling pathway. Exp Ther Med 9: 1401-1406, 2015.

3. Pappalardo F, Russo G, Candido S, Pennisi M, Cavalieri S, Motta S, McCubrey JA, Nicoletti F and Libra M: Computational modeling of PI3K/AKT and MAPK signaling pathways in melanoma cancer. PLoS One 11: e0152104, 2016.

4. Vujic I, Sanlorenzo M, Posch C, Esteve-Puig R, Yen AJ, Kwong A, Tsumura A, Murphy R, Rappersberger K and Ortiz-Urda S: Metformin and trametinib have synergistic effects on cell viability and tumor growth in NRAS mutant cancer. Oncotarget 6: 969-978, 2015

5. Zhou BP, Liao Y, Xia W, Zou Y, Spohn B and Hung MC: HER-2/neu induces p53 ubiquitination via Akt-mediated MDM2 phosphorylation. Nat Cell Biol 3: 973-982, 2001.
6. Ashcroft M, Ludwig RL, Woods DB, Copeland TD, Weber HO, MacRae EJ and Vousden KH: Phosphorylation of HDM2 by Akt. Oncogene 21: 1955-1962, 2002

7. Dong C, Zhao B, Long F, Liu Y, Liu Z, Li S, Yang X, Sun D, Wang H, Liu Q, et al: Nogo-B receptor promotes the chemoresistance of human hepatocellular carcinoma via the ubiquitination of p53 protein. Oncotarget 7: 8850-8865, 2016.

8. Decensi A, Puntoni M, Goodwin P, Cazzaniga M, Gennari A, Bonanni B and Gandini S: Metformin and cancer risk in diabetic patients: A systematic review and meta-analysis. Cancer Prev Res (Phila) 3: 1451-1461, 2010.

9. Franciosi M, Lucisano G, Lapice E, Strippoli GF, Pellegrini F and Nicolucci A: Metformin therapy and risk of cancer in patients with type 2 diabetes: Systematic review. PLoS One 8: e71583, 2013.

10. Rocha GZ, Dias MM, Ropelle ER, Osório-Costa F, Rossato FA, Vercesi AE, Saad MJ and Carvalheira JB: Metformin amplifies chemotherapy-induced AMPK activation and antitumoral growth. Clin Cancer Res 17: 3993-4005, 2011.

11. Würth R, Pattarozzi A, Gatti M, Bajetto A, Corsaro A, Parodi A, Sirito R, Massollo M, Marini C, Zona G, et al: Metformin selectively affects human glioblastoma tumor-initiating cell viability: A role for metformin-induced inhibition of Akt. Cell Cycle 12: 145-156, 2013.

12. Song CW, Lee H, Dings RP, Williams B, Powers J, Santos TD, Choi $\mathrm{BH}$ and Park HJ: Metformin kills and radiosensitizes cancer cells and preferentially kills cancer stem cells. Sci Rep 2: $362,2012$.

13. He G, Zhang YW, Lee JH, Zeng SX, Wang YV, Luo Z, Dong XC, Viollet B, Wahl GM and Lu H: AMP-activated protein kinase induces p53 by phosphorylating MDMX and inhibiting its activity. Mol Cell Biol 34: 148-157, 2014.

14. Wang H, Ma X, Ren S, Buolamwini JK and Yan C: A small-molecule inhibitor of MDMX activates p53 and induces apoptosis. Mol Cancer Ther 10: 69-79, 2011.

15. Ravishankar D, Rajora AK, Greco F and Osborn HM: Flavonoids as prospective compounds for anti-cancer therapy. Int $\mathrm{J}$ Biochem Cell Biol 45: 2821-2831, 2013.

16. Sak K: Cytotoxicity of dietary flavonoids on different human cancer types. Pharmacogn Rev 8: 122-146, 2014.

17. Kim SJ, Kim HJ, Kim HR, Lee SH, Cho SD, Choi CS, Nam JS and Jung JY: Antitumor actions of baicalein and wogonin in HT-29 human colorectal cancer cells. Mol Med Rep 6: 1443-1449, 2012.

18. Koosha S, Alshawsh MA, Looi CY, Seyedan A and Mohamed Z: An association map on the effect of flavonoids on the signaling pathways in colorectal cancer. Int J Med Sci 13: 374-385, 2016.

19. Hirano T, Abe K, Gotoh M and Oka K: Citrus flavone tangeretin inhibits leukaemic HL-60 cell growth partially through induction of apoptosis with less cytotoxicity on normal lymphocytes. Br J Cancer 72: 1380-1388, 1995.

20. Iakovleva I, Begum A, Pokrzywa M, Walfridsson M, Sauer-Eriksson AE and Olofsson A: The flavonoid luteolin, but not luteolin-7-O-glucoside, prevents a transthyretin mediated toxic response. PLoS One 10: e0128222, 2015.

21. El-Naga RN: Pre-treatment with cardamonin protects against cisplatin-induced nephrotoxicity in rats: Impact on NOX-1, inflammation and apoptosis. Toxicol Appl Pharmacol 274: 87-95, 2014.

22. Wenzel U, Kuntz S, Brendel MD and Daniel H: Dietary flavone is a potent apoptosis inducer in human colon carcinoma cells. Cancer Res 60: 3823-3831, 2000.

23. Herzog A, Kindermann B, Döring F, Daniel H and Wenzel U: Pleiotropic molecular effects of the pro-apoptotic dietary constituent flavone in human colon cancer cells identified by protein and mRNA expression profiling. Proteomics 4: 2455-2464, 2004.

24. Lin CH, Chang CY, Lee KR, Lin HJ, Chen TH and Wan L: Flavones inhibit breast cancer proliferation through the Akt/FOXO3a signaling pathway. BMC cancer 15: 958, 2015.

25. Quinn BJ, Kitagawa H, Memmott RM, Gills JJ and Dennis PA: Repositioning metformin for cancer prevention and treatment. Trends Endocrinol Metab 24: 469-480, 2013.

26. Cerezo M, Tomic T, Ballotti R and Rocchi S: Is it time to test biguanide metformin in the treatment of melanoma? Pigment Cell Melanoma Res 28: 8-20, 2015.

27. Manning BD and Cantley LC: AKT/PKB signaling: Navigating downstream. Cell 129: 1261-1274, 2007.

28. Mamane Y, Petroulakis E, Rong L, Yoshida K, Ler LW and Sonenberg N: eIF4E-from translation to transformation. Oncogene 23: 3172-3179, 2004. 
29. Chou CC, Lee KH, Lai IL, Wang D, Mo X, Kulp SK, Shapiro CL and Chen CS: AMPK reverses the mesenchymal phenotype of cancer cells by targeting the Akt-MDM2-Foxo3a signaling axis. Cancer Res 74: 4783-4795, 2014.

30. Franzen CA, Amargo E, Todorović V, Desai BV, Huda S Mirzoeva S, Chiu K, Grzybowski BA, Chew TL, Green KJ and Pelling JC: The chemopreventive bioflavonoid apigenin inhibits prostate cancer cell motility through the focal adhesion kinase/Src signaling mechanism. Cancer Prev Res (Phila) 2: 830-841, 2009.

31. Shukla S, Bhaskaran N, Babcook MA, Fu P, Maclennan GT and Gupta S: Apigenin inhibits prostate cancer progression in TRAMP mice via targeting PI3K/Akt/FoxO pathway. Carcinogenesis 35: 452-460, 2014

32. Zhu W, Yang B, Fu H, Ma L, Liu T, Chai R, Zheng Z, Zhang Q and Li G: Flavone inhibits nitric oxide synthase (NOS) activity, nitric oxide production and protein S-nitrosylation in breast cancer cells. Biochem Biophys Res Commun 458: 590-595, 2015.

33. Seo YJ, Kim BS, Chun SY, Park YK, Kang KS and Kwon TG: Apoptotic effects of genistein, biochanin-A and apigenin on LNCaP and PC-3 cells by p21 through transcriptional inhibition of polo-like kinase-1. J Korean Med Sci 26: 1489-1494, 2011.

34. Dey N, De P and Leyland-Jones B: PI3K-AKT-mTOR inhibitors in breast cancers: From tumor cell signaling to clinical trials. Pharmacol Ther 175: 91-106, 2017.

35. Sarbassov DD, Guertin DA, Ali SM and Sabatini DM: Phosphorylation and regulation of Akt/PKB by the rictor-mTOR complex. Science 307: 1098-1101, 2005.

36. Ling X, Xu C, Fan C, Zhong K, Li F and Wang X: FL118 induces p53-dependent senescence in colorectal cancer cells by promoting degradation of MdmX. Cancer Res 74: 7487-7497, 2014.
37. Zhang X, Wu H, Liu C, Tian J and Qu L: PI3K/Akt/p53 pathway inhibits reovirus infection. Infect Genet Evol 34: 415-422, 2015.

38. Ben-Sahra I, Dirat B, Laurent K, Puissant A, Auberger P, Budanov A, Tanti JF and Bost F: Sestrin2 integrates Akt and mTOR signaling to protect cells against energetic stress-induced death. Cell Death Differ 20: 611-619, 2013.

39. Li T: Pacilitaxel induces human nasopharyngeal carcinoma cell line CNE2 apoptosis and growth inhibition by suppressing $\mathrm{PI} 3 \mathrm{~K} / \mathrm{AKT} / \mathrm{p} 53$ signaling pathway. Lin Chung Er Bi Yan Hou Tou Jing Wai Ke Za Zhi 29: 2147-2150, 2015 (In Chinese).

40. Chipuk JE, Kuwana T, Bouchier-Hayes L, Droin NM, Newmeyer DD, Schule M and Green DR: Direct activation of Bax by 553 mediates mitochondrial membrane permeabilization and apoptosis. Science 303: 1010-1014, 2004.

41. Miyashita T, Krajewski S, Krajewska M, Wang HG, Lin HK, Liebermann DA, Hoffman B and Reed JC: Tumor suppressor p53 is a regulator of bcl-2 and bax gene expression in vitro and in vivo. Oncogene 9: 1799-1805, 1994

42. Zhong LR, Chen X and Wei KM: Radix tetrastigma hemsleyani flavone induces apoptosis in human lung carcinoma a549 cells by modulating the MAPK pathway. Asian Pac J Cancer Prev 14: 5983-5987, 2013

43. Lucas CD, Allen KC, Dorward DA, Hoodless LJ, Melrose LA, Marwick JA, Tucker CS, Haslett C, Duffin R and Rossi AG: Flavones induce neutrophil apoptosis by down-regulation of Mcl-1 via a proteasomal-dependent pathway. FASEB J 27: 1084-1094, 2013. 